\title{
Carlos Javier MoReIro GonzÁlez, La invocación del plazo razonable ante el Tribunal de Justicia, Dykinson, Madrid, 2012
}

La monografía del Profesor Carlos Moreiro constituye una obra fundamental para los operadores que se enfrenten a procedimientos de contenido comunitario económico y a los cauces que les ofrecen los diferentes sistemas supranacionales para conseguir una adecuada protección de sus derechos.

El libro hace fundamentalmente referencia a la relevancia que la protección del principio de celeridad tiene actualmente en los procedimientos judiciales. Sin celeridad procesal no puede existir calidad en la justicia, de ahí la importancia que tiene un análisis de la protección que recibe el principio de proceso sin dilaciones indebidas.

Desde una perspectiva internacional publicista, el enfoque del autor resulta de especial interés, dado que partiendo del estudio del principio en el sistema de Naciones Unidas, pasa por el Consejo de Europa y la Unión Europea para llegar a los sistemas nacionales de protección de derechos fundamentales. Es una comparación a la par académicamente brillante y de elevada eficacia práctica.

El análisis que el autor realiza de la jurisprudencia del Tribunal Europeo de Derechos Humanos y en el Tribunal Constitucional español puede considerarse profundo y lleno de matices y esto convierte a esta obra en un referente necesario para los operadores de diversa índole que se enfrenten a la defensa de derechos particulares ante las instancias jurisdiccionales.

El tratamiento del principio parte de la propia definición del concepto jurídico indeterminado en que se basa, es decir, aborda la noción de derecho al plazo razonable. Esta definición parte del estudio de las condiciones para su invocación ante los tribunales y de las medidas que los sistemas contienen para poder garantizar su ejercicio y teniendo en cuenta su falta de definición normativa, emplea los requisitos jurisprudenciales definidos por las diferentes instancias que han abordado la cuestión. El análisis de la confluencia de aproximaciones sobre el mismo principio, basándose en diferentes elementos y matices se aborda por el autor con delicadeza y precisión jurídica dignas de ser subrayadas. Es quizá la referencia a elementos contenidos en normas universales formales o pertenecientes al soft law, a pesar de no ser el centro fundamental de interés de la monografía, uno de los elementos más novedosos y relevantes de este análisis y en el que el autor pone a disposición del lector su dominio del complejo entramado normativo en que en este momento se han convertido nuestros ordenamientos.

El primer capítulo, bajo la denominación Características generales del derecho a un proceso sin dilaciones indebidas (págs. 13-44) analiza la definición del derecho a obtener una resolución judicial en un plazo razonable en el Derecho español, el supranacional, el Derecho de la Unión Europea, y en la jurisprudencia del TEDH. 
El capítulo segundo del libro bajo el título Consideraciones sobre la naturaleza y el funcionamiento del sistema jurisdiccional de la unión Europea, (págs. 45-74) hace un análisis teórico y doctrinal de la relevancia de la jurisprudencia comunitaria en razón de la naturaleza del Tribunal de Justicia como máxima instancia encargada de controlar la labor de los órganos administrativos comunitarios.

La necesidad de celeridad se pone en conexión con la cautela que exige la protección de los derechos de defensa de las partes y se analizan las razones que determinan la complejidad de los procedimientos y los esfuerzos que se han llevado a cabo para tratar de paliar los efectos negativos de esa complejidad sin descuidar el resto de valores que se protegen en el procedimiento.

El capítulo tercero se denomina La doctrina del Tribunal de Justicia sobre la duración razonable de los procedimientos (págs. 75-120). En el se analiza la jurisprudencia del TJ en procedimientos en que se alega la vulneración del derecho a que la causa sea vista en un plazo razonable y en él se pone de manifesto nuevamente la relación existente entre el análisis comunitario y el del Consejo de Europa vía Tribunal Europeo de Derechos Humanos.

El análisis de las similitudes y diferencias entre ambas instancias en el enfoque del principio, la definición de los matices que separan la aproximación entre ambas instancias resulta uno de los aspectos más relevantes de la monografía objeto de estudio.

Además se aborda otra de las cuestiones más relevantes en la aplicación práctica del principio, la determinación de los sistemas jurídicos para reparar los perjuicios que en las personas físicas y jurídicas implique la violación del derecho a un proceso sin dilaciones indebidas.

En esta cuestión se verifica otro de los elementos que subrayan la relevancia práctica de este estudio para los operadores jurídicos que busquen proteger derechos económicos ante instancias nacionales o internacionales, tratando de acercarnos a una justicia eficaz y respetuosa con los derechos de los ciudadanos.

\author{
María Pilar Canedo Arrillaga \\ Jean Monnet Chair en Derecho Transnacional \\ Universidad de Deusto
}

